\title{
Changes in $\beta$-Cell Function in Offspring of Type- 2 Diabetic Patients, as per Fasting and Two-Hour Plasma Glucose Levels
}

Edavan Pulikkanath Praveen ${ }^{1}$, Sunil Chouhan ${ }^{2}$, Jayaprakash Sahoo ${ }^{3}$, Rajesh Khadgawat ${ }^{4}$, Madan Lal Khurana ${ }^{4}$, Nandita Gupta ${ }^{4}$, Sada Nand Dwivedi ${ }^{5}$, Bindu Kulshreshtha ${ }^{6}$

1. Biochemistry, Sindhudurg Shikshan Prasarak Mandal (SSPM) Medical College and Lifetime Hospital, Sindhudurg, IND 2. Physiology, All India Institute of Medical Sciences (AIIMS), Bhopal, IND 3. Endocrinology, Jawaharlal Institute of Postgraduate Medical Education \& Research (JIPMER), Puducherry, IND 4. Endocrinology, All India Institute of Medical Sciences (AIIMS), New Delhi, IND 5. Biostatistics, All India Institute of Medical Sciences (AIIMS), New Delhi, IND 6. Endocrinology, Atal Bihari Vajpayee Institute of Medical Sciences (ABVIMS), New Delhi, IND

Corresponding author: Edavan Pulikkanath Praveen, praveenbiomed@gmail.com

\section{Abstract}

\section{Background}

The changes in $\beta$-cell function in high-risk populations who are apparently in the normal glucose tolerant stage are still under investigation for designing earlier prevention strategies. This study analyzes changes in $\beta$-cell function and insulin sensitivity across fasting and two-hour glucose categories spanning normal glucose tolerance (NGT) to impaired glucose tolerance (IGT), in offspring of subjects with type-2 diabetes mellitus (T2DM) compared to the controls without a known family history of T2DM.

\section{Methods}

Offspring of T2DM patients (cases) and individuals without a family history of T2DM (controls) were the subjects for this cross-sectional study. All participants underwent a $75 \mathrm{~g}$ oral glucose tolerance test and blood samples were collected for plasma glucose, insulin, C-peptide and proinsulin, at zero, 30, 60, and 120 minutes.

\section{Results}

A total of 358 cases (age $23.0 \pm 10.8$ years, $54 \%$ males) and 287 controls (age $28.4 \pm 8.10$ years, $65 \%$ males) were the subjects of this study. Cases and controls were divided into subgroups based on fasting and twohour glucose categories spanning NGT to IGT. Compared to the reference category of controls ( $<80 \mathrm{mg} / \mathrm{dL}$ for fasting glucose and $<84 \mathrm{mg} / \mathrm{dL}$ for two-hour glucose), cases with IGT had $\sim 60 \%$ decline in both $\beta$-cell compensation (as measured as disposition index $\{0-120\}$ ) and insulin sensitivity (as measured as whole-body insulin sensitivity index $\{0-120\}$ ); adjusted for age, gender, and body mass index. From lower to higher fasting and two-hour glucose categories, there was a continuous and significant decline in $\beta$-cell

Review began 03/15/2021 Review ended 05/09/2021 Published 05/16/2021

\section{๑) Copyright 2021}

Praveen et al. This is an open access article distributed under the terms of the Creative Commons Attribution License CC-BY 4.0., which permits unrestricted use, distribution, and reproduction in any medium, provided the original author and source are credited. compensation in both cases and controls. Significant reduction in first-phase insulin secretion, as measured as insulinogenic (0-30) index, was only observed among two-hour glucose categories, not among the fasting glucose categories. In the transition from late NGT cases to IGT cases, there was a significant decline in $\beta$ cell compensation, first-phase insulin secretion (more prominent than a decline in overall $\beta$-cell secretion) and the changes in whole-body insulin sensitivity were not statistically significant.

\section{Conclusions}

The decline in $\beta$-cell compensation was continuous and significant in offspring of subjects with type-2 diabetes and controls without a known family history of diabetes from early normal glucose tolerant ranges to impaired glucose tolerant ranges. Compared to the strictest glucose controlled category of controls, approximately $60 \%$ decline was observed in $\beta$-cell compensation and insulin sensitivity, in impaired glucose tolerant offspring of subjects with type-2 diabetes mellitus.

Categories: Endocrinology/Diabetes/Metabolism

Keywords: two-hour glucose categories, fasting glucose categories, offspring of subjects with $\mathrm{t} 2 \mathrm{dm}$, $\beta$-cell compensation, continuum, insulin sensitivity, first-phase insulin secretion, $\beta$-cell secretion

\section{Introduction}

Maintenance of normal glucose tolerance depends on a finely tuned balance between insulin sensitivity and $\beta$-cell function [1]. The concept that a feedback loop governs the interaction of the insulin-sensitive tissues and the $\beta$-cell, as well as the elucidation of the hyperbolic relationship between insulin secretion and insulin sensitivity, explains the elevated insulin response in insulin-resistant subjects and a lower response in insulin-sensitive subjects [2]. Consideration of this hyperbolic relationship has helped to recognize the 
critical role of $\beta$-cell dysfunction, in the development of impaired glucose tolerance and type-2 diabetes [3]. Assessment of several ethnic groups has shown a progressive reduction in $\beta$-cell function from normal to impaired glucose tolerance and subsequently to type-2 diabetes, accompanied by a decline in insulin sensitivity $[1,4]$. The progressive nature of $\beta$-cell function in type- 2 diabetes mellitus (T2DM) was also established in landmark clinical studies [5]. The therapeutic or lifestyle interventions should address the underlying pathology and should be started early along the spectrum of glucose tolerance to prevent declining insulin sensitivity and $\beta$-cell failure [6].

Normal glucose tolerance is expressed over a wide range of glucose concentrations; postprandial glucose concentration from about $70 \mathrm{mg} / \mathrm{dL}$ to $139 \mathrm{mg} / \mathrm{dL}$. In normal glucose-tolerant subjects, insulin sensitivity and insulin secretion varied over a large range. According to a study in obese youth by Yeckel et al., insulin secretion as measured by the insulinogenic index has a strong impact on postprandial glucose levels even within the normal range, and in all insulin sensitivity tertiles [7]. Studies have suggested that reduced $\beta$-cell function manifested as reduced insulin release is a prerequisite for the progression from normal glucose tolerance (NGT) to hyperglycemia [8]. Most cross-sectional studies regarding the changes in $\beta$-cell function as a continuum from NGT to impaired glucose tolerance (IGT) were performed in older subjects or obese populations and the reference category was also similar. The offspring of type-2 diabetic patients of Indian origin is a younger population, vulnerable to hyperglycemia [9]. This cross-sectional study aimed to analyze the magnitude of changes in $\beta$-cell compensation, insulin sensitivity, first-phase insulin secretion, and proinsulin levels during oral glucose tolerance test, across fasting and two-hour glucose levels spanning NGT to IGT, in a relatively younger Indian origin population of offspring of subjects with T2DM, compared with a stricter glucose controlled group with no known family history of T2DM.

\section{Materials And Methods}

The participants in this research were descendants of patients with T2DM and people without a known family history of T2DM. Our sampling frame was the "offspring of individuals with T2DM" study database [10]. The study protocol was approved by the ethics committee of the All India Institute of Medical Sciences (AIIMS), New Delhi.

\section{Recruitment of cases}

Patients who were undergoing treatment for T2DM in the endocrine clinic of AIIMS, New Delhi, were informed about this study and asked to invite their children and grandchildren to participate. Only children and grandchildren with ages ranging from five to 55 years were included. Those with diabetes mellitus, pregnancy, lactation, or presence of any chronic illness were excluded.

\section{Recruitment of controls}

In addition to requiring age to be between five years and 55 years, controls had to have a negative history of T2DM in parents, siblings, and grandparents. Students and members of residents' associations of different areas were informed about the study with the help of a medical social worker. The study details were explained during group discussions. The exclusion criteria were the same as those for the cases.

Detailed family history was recorded for all participants, with emphasis on the history of T2DM in parents, siblings, and grandparents. For the oral glucose tolerance test (OGTT), subjects were advised to maintain their normal diet and abstain from alcohol for three days prior to the test. After 10 to 12 hours of overnight fast, the OGTT was performed using a $75 \mathrm{~g}(1.75 \mathrm{~g} / \mathrm{kg}$ body weight in the case of children, up to a maximum dose of $75 \mathrm{~g}$ ) oral glucose dose. Blood samples were collected at zero, 30, 60, and 120 minutes after oral glucose dosing, from which to determine plasma glucose, insulin, C-peptide, and proinsulin measurements. Glucose tolerance was determined by American Diabetes Association 2003 criteria [11].

\section{Analytical measurements}

Plasma glucose was measured by the glucose oxidase method on a Labmate-20 analyzer (Trivitron Diagnostics, Chennai, India). Plasma insulin and C-peptide were measured by electro-chemiluminescence assay by Elecsys 2010 (Roche Diagnostics, Indianapolis, USA). The insulin assay uses monoclonal antibodies against insulin and has $0.05 \%$ cross-reactivity with human proinsulin and its split forms. The intra-assay coefficient of variation (CV) for insulin assay was 5.1\% and inter-assay CV was 5.7\%. For C-peptide, intraassay CV was $3.8 \%$ and inter-assay CV was 3.9\%. Plasma proinsulin was measured by a radioimmunoassay kit (Catalog no. HPI-15K, Millipore Corporation, Billerica, MA). This assay cross-reacts neither with human insulin $(<0.1 \%)$ nor with C-peptide $(0.1 \%)$. It has $100 \%$ specificity for intact human proinsulin and $95 \%$ with des-31, 32 human proinsulin. Intra and inter-assay CV of proinsulin assay were $5.9 \%$ and $6.9 \%$, respectively.

The area under the curve (AUC) was calculated according to Tai's formula. Area under the curve (AUC) $=15$ $[(x 1+x 2)+(x 2+x 3)+2(x 3+x 4)]$, where $x 1, x 2, x 3$, and $x 4$ were respective values on time points zero, 30,60 , and two-hours during OGTT [12]. Whole-body insulin sensitivity was measured as whole-body insulin sensitivity index (WBISI) as described by Matsuda et al [13]. Homeostasis model assessment-insulin resistance (HOMAIR) was measured as proposed by Matthews et al. [14]. AUC of C-peptide (0-120) was divided by AUC of glucose (0-120) to determine insulinogenic index (0-120) [IGI 120], a measure of $\beta$-cell secretion, as 
described by Stadler et al. [15]. Disposition index (0-120) [DI 120] was calculated as the product of IGI 120 and WBISI, making a variation from the formula described by Retnakaran et al., [16] where plasma insulin was used in the place of C-peptide for the measurement of IGI 120. Insulinogenic index (0-30) (insulin in pmol/1 \{30-0 minute $\}) /($ glucose in mmol/1 \{30-0 minute $\}$ ) was calculated as a measure of first-phase insulin secretion [17].

\section{Statistical analysis}

Statistical analysis was done using Statistical Package for the Social Sciences (SPSS) version 15 software (Chicago, IL: SPSS Inc.). For comparison of parameters between two groups, Student's unpaired t-test was used. A chi-square test was used to compare categorical variables. The quantitative continuous data were expressed as mean \pm SD or mean \pm SE values. Skewed data were normalized by applying log transformation for insulin, C-peptide, proinsulin, HOMA-IR, WBISI, IGI-120, IGI-30, and DI-120. The general linear model was used for comparing different groups after adjusting for confounding variables age, gender, and BMI. Post hoc comparison was done by Bonferroni's method. Tests were considered significant at $\mathrm{p}<0.05$.

\section{Results}

A total of 645 subjects were participated in the study and underwent OGTT. Out of 645 subjects, 358 were with a family history of T2DM (cases) and 287 without a known family history of T2DM (controls).

There were 358 cases, among them, 301 were of normal glucose tolerance and 47 were having impaired glucose tolerance/impaired fasting glucose (IGT/IFG) and 10 subjects were newly diagnosed with diabetes. There were 287 cases, among them, 259 were normal glucose tolerant and 28 were having IGT/IFG.

The mean age of cases was $23.0 \pm 10.8$ (mean \pm SD) years and that of controls was $28.4 \pm 8.10$ years (significantly higher age in controls, $\mathrm{p}<0.001$ ). Out of 358 cases, 194 (54\%) were males and out of 287 controls, 187 (65\%) were males (significantly higher percentage of males in controls, $p=0.006$ ). There were 128 (35.6\%) cases who had a mother with T2DM, 119 (33\%) had a father with T2DM, 37 (10\%) had both parents with T2DM and 74 (20.7\%) of cases had one or more grandparents with T2DM (their parents were non-diabetic). Mean BMI of cases was higher $23.5 \pm 6.0$ (mean $\pm \mathrm{SD}$ ) kg/ $\mathrm{m}^{2}$ (range 11.5-47.6) compared to $22.2 \pm 3.9 \mathrm{~kg} / \mathrm{m}^{2}$ of controls, (range $12-41.5 ; \mathrm{p}=0.001$ ).

Cases ( $\mathrm{n}=348$ ) were divided into four groups according to fasting glucose (FG) and analyzed (10 newly diagnosed diabetic cases were excluded from this analysis due to limited numbers) (Table 1).

\begin{tabular}{|c|c|c|c|c|c|}
\hline Parameters & $\begin{array}{l}\mathrm{FG} \leq 80 \mathrm{mg} / \mathrm{dL} \\
\mathrm{n}=81 \text { mean } \pm S E\end{array}$ & $\begin{array}{l}\mathrm{FG} 81-90 \mathrm{mg} / \mathrm{dL} \\
\mathrm{n}=158 \text { mean } \pm S E\end{array}$ & $\begin{array}{l}\mathrm{FG} 91-99 \mathrm{mg} / \mathrm{dL} \\
\mathrm{n}=81 \text { mean } \pm S E\end{array}$ & $\begin{array}{l}\mathrm{FG} 100-126 \mathrm{mg} / \mathrm{dL} \\
\mathrm{n}=28 \text { mean } \pm \mathrm{SE}\end{array}$ & $\begin{array}{l}\text { p- } \\
\text { Value }\end{array}$ \\
\hline $\begin{array}{l}\text { AUC proinsulin (nmolL”per } 120 \\
\text { minute) }\end{array}$ & $4.76 \pm 0.24$ & $4.89 \pm 0.2$ & $5.3 \pm 0.3$ & $6.8 \pm 0.4$ & 0.001 \\
\hline AUC proinsulin /AUC C-peptide & $0.019 \pm 0.001$ & $0.019 \pm 0.001$ & $0.019 \pm 0.001$ & $0.021 \pm 0.002$ & 0.541 \\
\hline HOMA-IR $(\mu \mathrm{U} / \mathrm{mL}, \mathrm{mmol} / \mathrm{L})$ & $1.7 \pm 0.24$ & $2.6 \pm 0.17$ & $3.0 \pm 0.2$ & $4.7 \pm 0.4$ & 0.001 \\
\hline WBISI ( $\mu \mathrm{U} / \mathrm{mL}, \mathrm{mg} / \mathrm{dL})$ & $8.85 \pm 0.5$ & $6.1 \pm 0.4$ & $4.9 \pm 0.5$ & $3.7 \pm 0.9$ & 0.001 \\
\hline IGI $120(\mathrm{nmol} / \mathrm{mmol})$ & $0.40 \pm 0.014$ & $0.37 \pm 0.009$ & $0.38 \pm 0.013$ & $0.36 \pm 0.023$ & 0.825 \\
\hline IGI 30 (pmol/mmol) & $244 \pm 32$ & $285 \pm 22$ & $310 \pm 31$ & $218 \pm 54$ & 0.407 \\
\hline $\begin{array}{l}\text { Disposition index (0-120) } \\
(\mathrm{nmol} / \mathrm{mmol}, \mu \mathrm{U} / \mathrm{mL}, \mathrm{mg} / \mathrm{dL})\end{array}$ & $2.7 \pm 0.09$ & $2.0 \pm 0.06$ & $1.6 \pm 0.09$ & $1.2 \pm 0.16$ & $\begin{array}{l}< \\
0.001\end{array}$ \\
\hline
\end{tabular}

TABLE 1: Insulin sensitivity and $\beta$-cell function of cases $(n=348)$ according to fasting glucose, after adjusting for age, gender, and BMI.

FG: fasting glucose; AUC: area under the curve; HOMA-IR: homeostasis model assessment-insulin resistance; WBISI: whole-body insulin sensitivity index; IGI: insulinogenic index

On post hoc analysis, after adjusting for age, gender and BMI, compared to $\leqslant 80$ categories of cases, there were significantly lower WBISI and disposition index (DI) 120 in 81-90, 91-99, and 100-126 mg/dl fasting 


\section{Cureus}

glucose category of cases. WBISI and DI 120 were also significantly lower in 100-126 mg/dL compared to 8190 and $91-99 \mathrm{mg} / \mathrm{dL}$ fasting categories. Insulinogenic indices were not significantly different. The area under the curve of proinsulin was significantly increased in IGT ranges compared to early NGT ranges.

Controls were also divided into four groups based on FG levels as done for cases. Among controls, there were 49 subjects in $\leqslant 80,128$ in $81-90,91$ in $91-99$ and 19 subjects in $100-126 \mathrm{mg} / \mathrm{dL}$ FG categories. FG $\leqslant 80 \mathrm{mg} / \mathrm{dL}$ was taken as a reference category. The percentage of reduction in WBISI, insulinogenic index (IGI 120) and disposition index (DI 120) in FG 81- 90 and 91-99 and 100-126 mg/dL categories in cases $(\mathrm{n}=348)$ and controls $(\mathrm{n}=287$ ) were calculated (Figure 1$)$. The analysis omitted 10 cases of newly diagnosed with type 2 diabetes due to limited numbers.

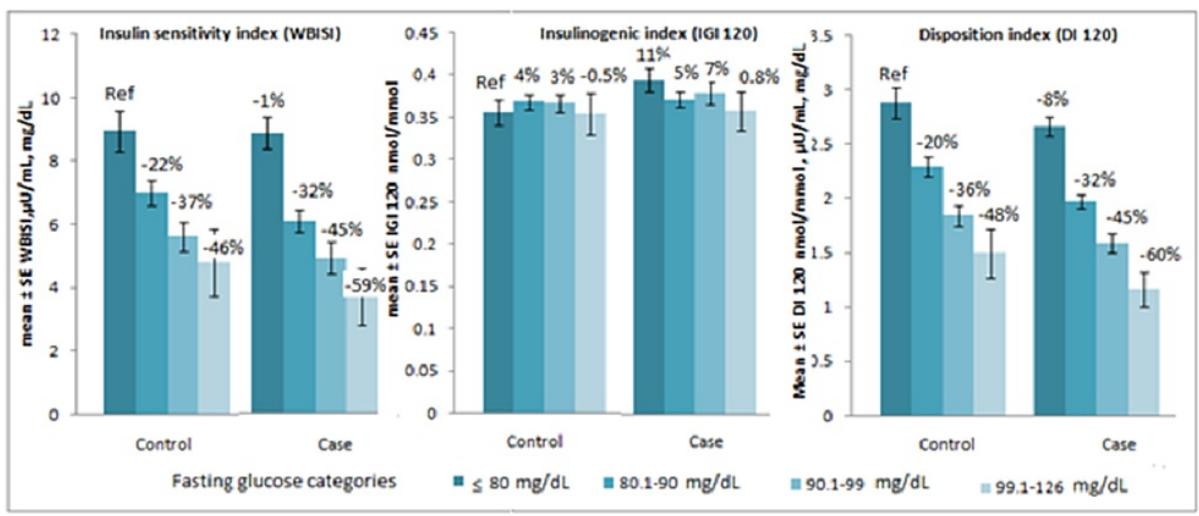

FIGURE 1: WBISI, IGI 120, and DI 120 according to fasting glucose categories in cases and controls, after adjusting for age, gender, and BMI.

WBISI: whole-body insulin sensitivity index; IGI: insulinogenic index; DI: disposition index

There was a gradual decline in insulin sensitivity and disposition index in both cases and controls as per the FG categories. In each category, cases have lower insulin sensitivity compared to controls.

Cases $(n=348)$ were divided into four groups according to two-hour glucose levels and were analyzed (10 diabetic cases were excluded from this analysis due to small numbers) (Table 2). 


\section{Cureus}

\begin{tabular}{|c|c|c|c|c|c|}
\hline Parameters & $\begin{array}{l}\text { 2-hour glucose < } \\
100 \mathrm{mg} / \mathrm{dL} \mathrm{n}=201 \\
\text { mean } \pm \text { SE }\end{array}$ & $\begin{array}{l}\text { 2-hour glucose 100- } \\
119 \mathrm{mg} / \mathrm{dL} \mathrm{n}=92 \\
\text { mean } \pm \text { SE }\end{array}$ & $\begin{array}{l}\text { 2-hour glucose 120- } \\
139 \mathrm{mg} / \mathrm{dL} \mathrm{n}=30 \\
\text { mean } \pm \mathrm{SE}\end{array}$ & $\begin{array}{l}\text { 2-hour glucose }>139 \\
\mathrm{mg} / \mathrm{dL} \quad \mathrm{n}=25 \\
\text { mean } \pm \mathrm{SE}\end{array}$ & $\begin{array}{l}\text { p- } \\
\text { Value }\end{array}$ \\
\hline $\begin{array}{l}\text { AUC proinsulin (nmolL- } \\
{ }^{1} \text { per } 120 \text { minute) }\end{array}$ & $4.65 \pm 0.15$ & $5.5 \pm 0.23$ & $6.1 \pm 0.4$ & $6.2 \pm 0.4$ & 0.001 \\
\hline $\begin{array}{l}\text { AUC proinsulin/AUC C- } \\
\text { peptide }\end{array}$ & $0.019 \pm 0.001$ & $0.019 \pm 0.001$ & $0.021 \pm 0.001$ & $0.020 \pm 0.002$ & 0.430 \\
\hline $\begin{array}{l}\text { HOMA-IR } \\
(\mu \mathrm{U} / \mathrm{mL}, \mathrm{mmol} / \mathrm{L})\end{array}$ & $2.44 \pm 0.16$ & $2.77 \pm 0.23$ & $3.03 \pm 0.41$ & $3.48 \pm 0.45$ & $\begin{array}{l}< \\
0.001\end{array}$ \\
\hline WBISI ( $\mu \mathrm{U} / \mathrm{mL}, \mathrm{mg} / \mathrm{dL})$ & $7.3 \pm 0.3$ & $4.8 \pm 0.5$ & $5.1 \pm 0.8$ & $4.2 \pm 0.9$ & $\begin{array}{l}< \\
0.001\end{array}$ \\
\hline IGI $120(\mathrm{nmol} / \mathrm{mmol})$ & $0.383 \pm 0.008$ & $0.396 \pm 0.012$ & $0.37 \pm 0.022$ & $0.297 \pm 0.023$ & 0.005 \\
\hline IGI 30 (pmol/mmol) & $325 \pm 20$ & $236 \pm 28$ & $249.5 \pm 49$ & $100.3 \pm 53$ & $\begin{array}{l}< \\
0.001\end{array}$ \\
\hline $\begin{array}{l}\text { Disposition index (0- } \\
120)(\mathrm{nmol} / \mathrm{mmol} \text {, } \\
\mu \mathrm{U} / \mathrm{mL}, \mathrm{mg} / \mathrm{dL})\end{array}$ & $2.3 \pm 0.06$ & $1.66 \pm 0.08$ & $1.52 \pm 0.15$ & $1.1 \pm 0.16$ & $\begin{array}{l}< \\
0.001\end{array}$ \\
\hline
\end{tabular}

TABLE 2: Insulin sensitivity and $\beta$-cell function of cases $(n=348)$ according to two-hour glucose categories, after adjusting for age, gender, and BMI.

AUC: area under the curve; HOMA-IR: homeostasis model assessment-insulin resistance; WBISI: whole-body insulin sensitivity index; IGI: insulinogenic index

On post hoc analysis, there were significantly higher AUC of proinsulin levels in 100-119, 120-139, >139 $\mathrm{mg} / \mathrm{dL}$ categories compared to $<100 \mathrm{mg} / \mathrm{dL}$, two-hour glucose category. HOMA-IR was significantly higher in $100-119$ and $>139$ categories compared to $<100 \mathrm{mg} / \mathrm{dL}$ category. WBISI of 100-119, 120-139 and $>139 \mathrm{mg} / \mathrm{dL}$ categories were significantly lower compared to $<100 \mathrm{mg} / \mathrm{dL}$ category. Between 100-119, 120-139, and $>139$ $\mathrm{mg} / \mathrm{dL}$ categories, WBISI was not significantly different. IGI (0-120) was significantly lower in the $>139$ $\mathrm{mg} / \mathrm{dL}$ category compared to $100-119$ and $<100 \mathrm{mg} / \mathrm{dL}$ and other comparisons were not significantly different. Compared to $<100 \mathrm{mg} / \mathrm{dL}$ two-hour glucose category, disposition index was significantly lower in 100-119, 120-139 and > $139 \mathrm{mg} / \mathrm{dl}$ two-hour glucose categories. Disposition index of $>139 \mathrm{mg} / \mathrm{dL}$ two-hour category was significantly lower compared to other lower glucose categories too.

Cases and controls were divided into smaller categories for analyzing the trends and magnitude of changes in $\beta$-cell compensation and insulin sensitivity according to two-hour glucose levels. The subjects were divided into eight categories according to glucose at two hours, spanning from NGT to IGT/DM. In cases, there were 71 subjects in < $84 \mathrm{mg} / \mathrm{dL}$ (two-hour glucose ), 98 in 84-95, 77 in 96-108, 35 in 109-115, 27 in 116125,17 in 126-139, 16 in 140-155, and 17 subjects in > $155 \mathrm{mg} / \mathrm{dL}$ category. In controls, there were 73 subjects in < $84 \mathrm{mg} / \mathrm{dL}$ (two-hour glucose category), 55 in 84-95, 68 in 96-108, 24 in 109-115, 40 in 116-125, 16 in $126-139$, and nine subjects in $140-155 \mathrm{mg} / \mathrm{dL}$ two-hour glucose category.

Less than $84 \mathrm{mg} / \mathrm{dL}$ two-hour glucose category of controls was taken as the reference category. The percentage of reduction in WBISI in different two-hour glucose categories from the reference group was given in Figure 2. 


\section{Cureus}

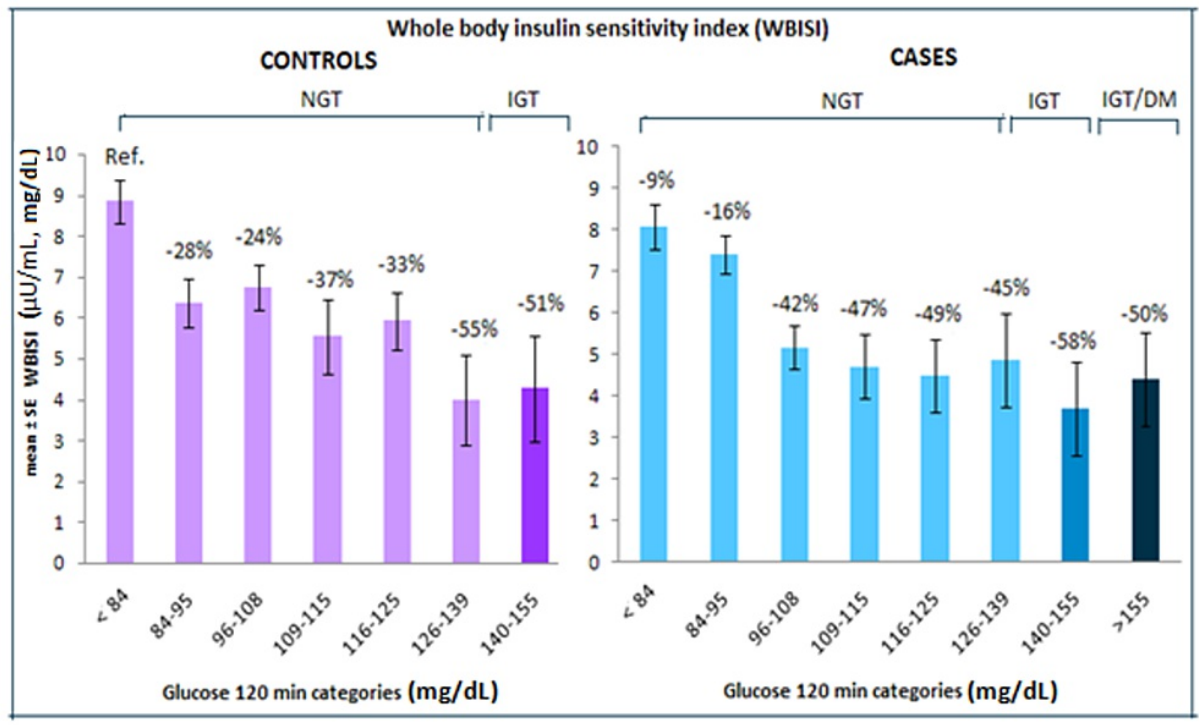

FIGURE 2: Change in WBISI in controls and cases across two-hour glucose categories, data were adjusted for age, gender, and BMI.

WBISI: whole-body insulin sensitivity index; NGT: normal glucose tolerance; IGT: impaired glucose tolerance; DM: diabetes mellitus

Both in cases and controls, there was a decline in insulin sensitivity across two-hour glucose categories however it was not a steady decline in both cases and controls. Overall lower insulin sensitivity was observed in cases compared to controls in the middle NGT ranges. From 126-139 mg/dL (two-hour glucose) onwards insulin sensitivity seems to be similar in both cases and controls. With a decline of insulin sensitivity of $47 \%$ in the 109-115 category compared to the reference category $(\mathrm{p}=0.02)$, there was no further significant change in late NGT and IGT/new DM categories of cases.

Compared to the two-hour reference category $(<84 \mathrm{mg} / \mathrm{dL}$ of controls), there was a trend of increase in $\beta$ cell secretion both in cases and controls in early NGT ranges, a trend of decline was observed from late NGT ranges $126-139 \mathrm{mg} / \mathrm{dL}$ ). A further decline was observed in IGT/new DM range (8-45\%) (Figure 3). 


\section{Cureus}

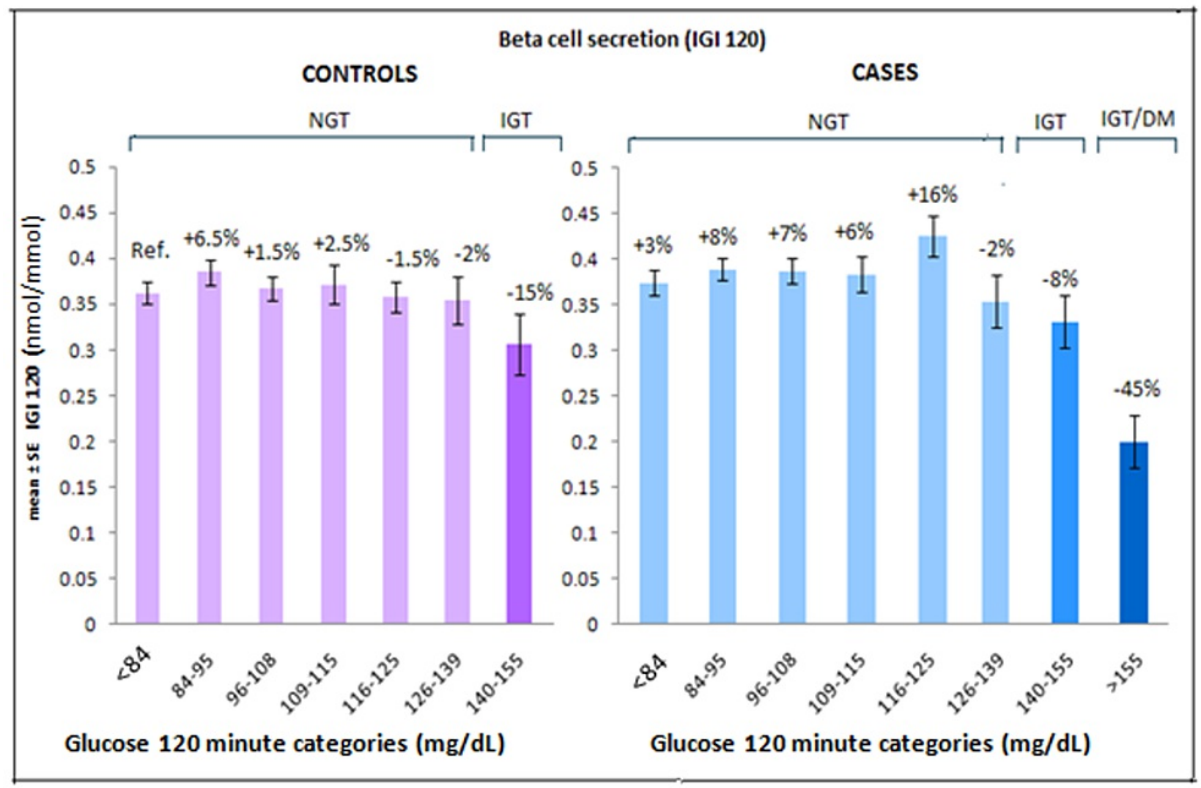

FIGURE 3: Change in $\beta$-cell secretion (IGI 120) in controls and cases across two-hour glucose categories, data were adjusted for age, gender, and BMI.

IGI: insulinogenic index; NGT: normal glucose tolerance; IGT: impaired glucose tolerance; DM: diabetes mellitus

There was a decline in first-phase insulin secretion as measured by IGI 30 of cases and controls compared to the reference category. In cases, the decline in IGI-30 was observed from 126-139 mg/dL two-hour glucose category and this seems to be in parallel with changes in the insulinogenic index (0-120), however, the decline was sharper (Figure 4).

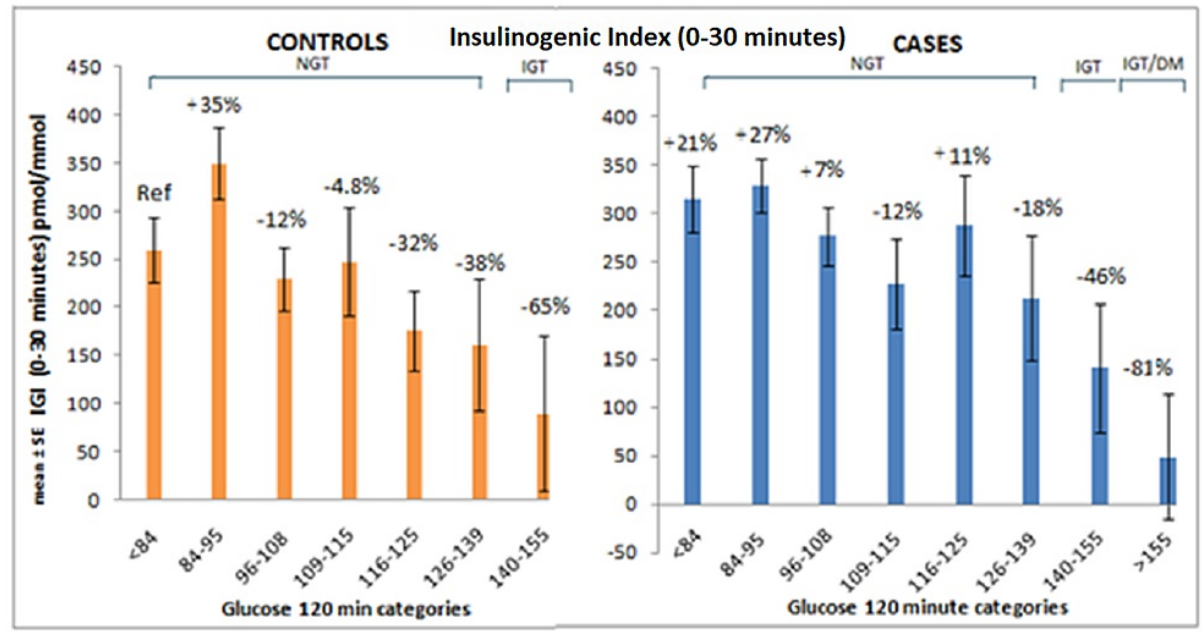

FIGURE 4: Changes in Insulinogenic index (0-30) in controls and cases across two-hour glucose categories, data were adjusted for age, gender, and BMI.

IGI: insulinogenic index; NGT: normal glucose tolerance; IGT: impaired glucose tolerance; DM: diabetes mellitus

There was a continuous and significant decline in $\beta$-cell compensation as measured by DI 120 in both controls and cases ( $<<0.001$; Figure 5). 


\section{Cureus}

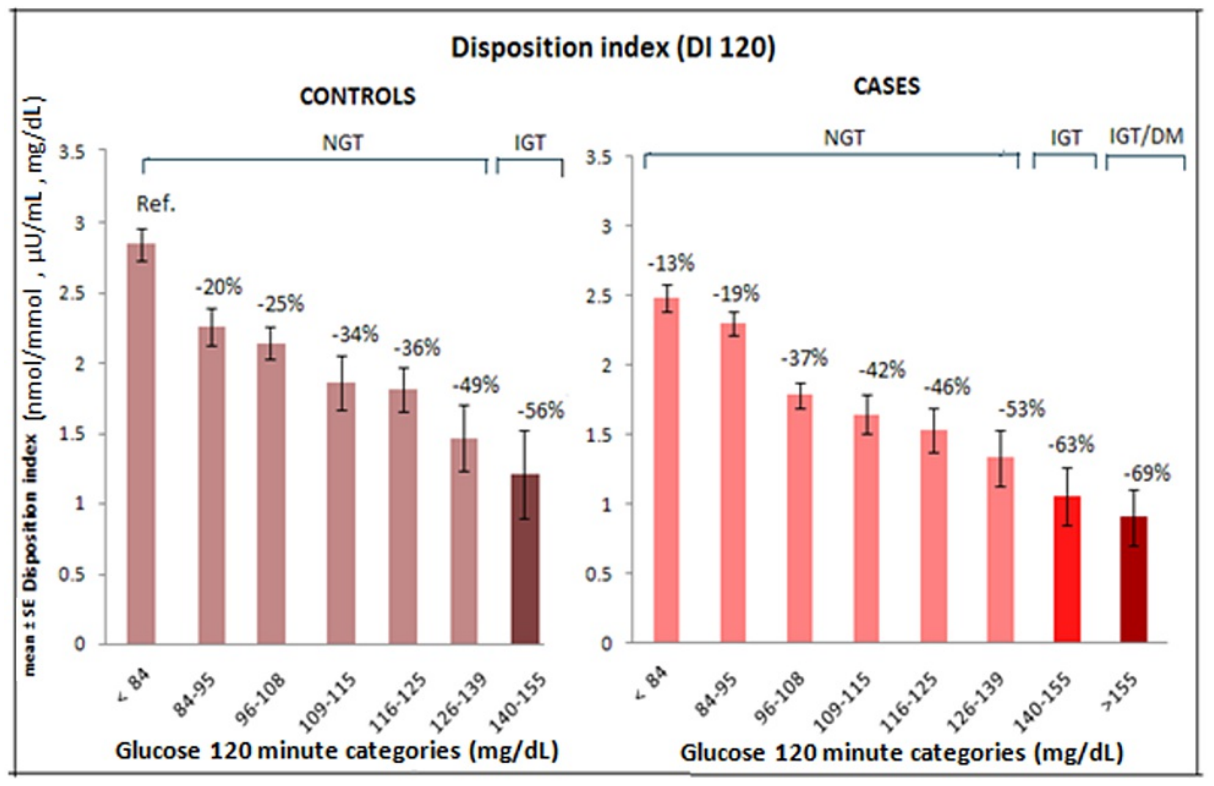

FIGURE 5: Change in $\beta$-cell compensation (DI 120) in controls and cases across 120-minute glucose categories, data were adjusted for age, gender, and BMI.

NGT: normal glucose tolerance; IGT: impaired glucose tolerance; DM: diabetes mellitus

In both cases and controls, there was a continuous decline in DI120 as two-hour glucose levels increased. Approximately 50\% reduction was observed in 126-139 category and a reduction of approximately $60 \%$ was observed in IGT two-hour ranges in cases compared to the reference two-hour category.

For studying the transition from normal to impaired glucose tolerance, normal glucose tolerant cases with two-hour glucose 116-139 mg/dL group were compared with IGT/IFG cases (Table 3). NGT cases with twohour glucose 116-125 and 126-139 mg/dL categories were combined into one group and compared with IGT/IFG group. 


\section{Cureus}

\begin{tabular}{|c|c|c|c|}
\hline & $\begin{array}{l}\text { NGT cases with 2-hour glucose (116-139) } n=33 \\
\text { mean } \pm \text { SE }\end{array}$ & $\begin{array}{l}\text { IGT/IFG cases } n=47 \\
\text { mean } \pm S E\end{array}$ & $\begin{array}{l}\text { p- } \\
\text { Value }\end{array}$ \\
\hline Plasma insulin 0 minutes $(\mu \mathrm{U} / \mathrm{mL})$ & $14.9 \pm 1.8$ & $16.8 \pm 1.5$ & 0.189 \\
\hline AUC glucose (mmolL ${ }^{-1}$ per 120 minutes) & $863 \pm 23$ & $995 \pm 19$ & $\begin{array}{l}< \\
0.001\end{array}$ \\
\hline AUC proinsulin $\left(\mathrm{nmolL}^{-1}\right.$ per 120 minutes & $6.38 \pm 0.37$ & $6.39 \pm 0.29$ & 0.765 \\
\hline AUC proinsulin/AUC C-peptide & $0.018 \pm 0.001$ & $0.018 \pm 0.001$ & 0.851 \\
\hline HOMA-IR ( $\mu \mathrm{U} / \mathrm{mL}, \mathrm{mmol} / \mathrm{L})$ & $3.3 \pm 0.4$ & $4.1 \pm 0.37$ & 0.051 \\
\hline WBISI ( $\mu \mathrm{U} / \mathrm{mL}, \mathrm{mg} / \mathrm{dL})$ & $3.7 \pm 0.28$ & $2.9 \pm 0.23$ & 0.116 \\
\hline IGI $120(\mathrm{nmol} / \mathrm{mmol})$ & $0.45 \pm 0.02$ & $0.37 \pm 0.02$ & 0.013 \\
\hline IGI 30 (pmol/mmol) & $276.6 \pm 37.6$ & $183 \pm 30.7$ & 0.004 \\
\hline $\begin{array}{l}\text { Disposition index (0-120) (nmol/mmol, } \\
\mu \mathrm{U} / \mathrm{mL}, \mathrm{mg} / \mathrm{dL})\end{array}$ & $1.4 \pm 0.07$ & $1.0 \pm 0.06$ & $\begin{array}{l}< \\
0.001\end{array}$ \\
\hline \multicolumn{4}{|c|}{$\begin{array}{l}\text { TABLE 3: Comparison of Insulin sensitivity and } \beta \text {-cell function between cases with two-hour } \\
\text { glucose } 116-139 \mathrm{mg} / \mathrm{dL} \text { and IGT/IFG cases. Data are adjusted for age, gender, and BMI. }\end{array}$} \\
\hline \multicolumn{4}{|c|}{$\begin{array}{l}\text { AUC: area under the curve; HOMA-IR: homeostasis model assessment-insulin resistance; WBISI: whole-body insulin sensitivity } \\
\text { index; IGI: insulinogenic index; NGT: normal glucose tolerance; IFG: }\end{array}$} \\
\hline
\end{tabular}

Insulin resistance as measured by HOMA-IR was higher in IGT/IFG group, had shown borderline significance $(p=0.051)$, however, WBISI was not significantly different between late NGT and IGT/IFG. AUC of proinsulin and AUC proinsulin to AUC C-peptide ratio was also not significantly different. A significant reduction was observed in IGI 30 (33\% reduction) and IGI120 (18\% reduction) and DI 120 (28\% reduction) in IGT, compared to the late NGT group.

\section{Discussion}

Type-2 diabetes mellitus is a global health concern. In the developed nations, it affects predominantly middle-aged and older populations; while in Asian countries like India and communities vulnerable to malnutrition, it affects the younger population [9]. The challenge to attain and maintain normoglycemia is compounded by the progressive nature of $\beta$-cell failure, which starts many years before the diagnosis of diabetes from the prediabetic stage or probably even before $[3,18]$. Subjects with a family history of T2DM are an ideal group to study the earliest abnormalities, as they are at higher risk for diabetes and abnormalities could be starting at a younger age $[15,19]$. In the present study, the mean age of subjects was in their twenties, reducing the confounding effects due to age. Whole-body insulin sensitivity in the present study was measured as WBISI as described by Matsuda and DeFronzo [13], which was shown to be having an excellent correlation with euglycemic hyperinsulinemic clamp technique by large scale studies [20]. The calculated disposition index by OGTT highlighted the inability of $\beta$-cell to compensate for declining insulin sensitivity [16]. In prospective studies, the disposition index declined well before glucose levels rise into the diabetic range, was mentioned as an early marker for inadequate $\beta$-cell compensation or $\beta$-cell dysfunction [21].

Metabolic Syndrome in Men (METSIM) study of the Finnish population was a large-scale study to evaluate the insulin sensitivity and insulin secretion over the entire range of fasting and two-hour plasma glucose, including diabetes [20]. The subjects were older and had higher BMI (mean age: 57 years, mean BMI: 27 $\mathrm{kg} / \mathrm{m}^{2}$ ). They used WBISI as a measure of insulin sensitivity, IGI 30 for early-phase insulin release, AUC insulin/AUC glucose as a marker for total insulin release, and disposition index (DI120 and DI30) as a $\beta$-cell response to insulin sensitivity. There was a $\sim 20 \%$ decline WBISI and $\sim 24 \%$ decline in DI 120 in the $90-97$ $\mathrm{mg} / \mathrm{dL}$ FG range compared to the reference range of $<90 \mathrm{mg} / \mathrm{dL}$ [20]. In the present study, subjects with a family history of T2DM (cases) were analyzed separately and compared with the reference group selected from controls. There was around $45 \%$ decline in insulin sensitivity and $\beta$-cell compensation in 90.1-99 $\mathrm{mg} / \mathrm{dL} \mathrm{FG}$ category of cases compared to $<80 \mathrm{mg} / \mathrm{dL}$ reference category. In the IGT ranges, the reduction in insulin sensitivity and $\beta$-cell compensation was $\sim 60 \%$. Compared to the $80-90 \mathrm{mg} / \mathrm{dL}$ FG group, cases in the 90-99 group has $\sim 23 \%$ decline in insulin sensitivity and disposition index and were comparable to the METSIM study. A study by Dagogo-Jack et al., divided subjects having normal fasting glucose into two groups, low normal fasting (low normal fasting glucose $\{\mathrm{NFG}\}<90 \mathrm{mg} / \mathrm{dL}$ ) and high-normal fasting (high NFG $90-99 \mathrm{mg} / \mathrm{dL}, \mathrm{n}=13$ ) and compared with impaired FG and combined IFT-IGT [22]. Compared to the low- 
normal FG group, the disposition index decreased by 33\% in the high normal FG group, 46\% in i-IFG subjects, and $50 \%$ in those with combined IFG-IGT. Three-fold variability in insulin sensitivity was reported in the $70-125 \mathrm{mg} / \mathrm{dL} \mathrm{FG}$ range [22]. In the present study, after adjusting for age, gender, and BMI, the variation in the mean insulin sensitivity was around 2.5 folds in the $70-125 \mathrm{mg} / \mathrm{dL}$ FG range. We observed lower insulin sensitivity and $\beta$-cell compensation in FG categories in cases compared to controls. This was similar to a study by Ehrmann et al., conducted in polycystic ovary syndrome (PCOS) subjects. PCOS with a family history of T2DM has shown a lower $\beta$-cell compensation for the degree of insulin resistance at all FG categories studied within the NGT range, compared to PCOS subjects without a family history of T2DM and women with no history of PCOS [23]. Proinsulin levels showed a progressive and significant increase from early NGT to IGT ranges in the current study. Significant hypersecretion of proinsulin with respect to the secretion of C-peptide levels during OGTT was not observed in the late NGT ranges, even though there was a trend of higher proinsulin to C-peptide ratio in IGT ranges. Studies have observed higher proinsulin to insulin ratio in diabetics, which could be because of inappropriate proinsulin processing due to various reasons like increased secretory demand on $\beta$-cell by chronic hyperglycemia or due to primary defect in the synthesis or secretion machinery [24]. As per our observations, unlike established diabetes, abnormal proinsulin processing may not be a feature of late NGT stages and the trend of relative hypersecretion of proinsulin may be starting from the IGT state.

San Antonio Metabolism (SAM) study had observed a greater than 50\% decline in the plasma insulin response to a glucose challenge in NGT individuals with two-hour plasma glucose between 110 to 140 $\mathrm{mg} / \mathrm{dL}$. IGT subjects with two-hour plasma glucose between $140 \mathrm{mg} / \mathrm{dL}$ and $200 \mathrm{mg} / \mathrm{dL}$ manifested a severely impaired plasma insulin response. The mean age of subjects was above 35 years in different categories [25]. In the METSIM study, the whole-body insulin sensitivity index (WBISI) reduced 37\% in the NGT range and $44 \%$ reduction in the IGT range, as a function of two-hour glucose levels. In the IGT and DM ranges, WBISI was almost similar. They observed a 30\% decline in disposition index (DI 120) in the late normal range and further decreased to $48 \%$ in the IGT range (<90 mg\% categories was taken as reference) [20]. Burns et al. studied overweight youth, showed $>30 \%$ decline in $\beta$-cell function relative to insulin sensitivity in late NGT ranges and $\sim 40 \%$ in IGT ranges, compared to $<120 \mathrm{mg} / \mathrm{dL}$ two-hour group [26]. In the current study, there was a $45 \%$ decline in insulin sensitivity in the late NGT ranges and a 50\% to $60 \%$ decline in the IGT ranges compared to the two-hour glucose reference category of $<84 \mathrm{mg} / \mathrm{dL}$ of controls. There was a decline of $53 \%$ in the disposition index in the late NGT and $\sim 63 \%$ decline in the disposition index in the IGT range. The higher reduction in insulin sensitivity and $\beta$-cell compensation in the current study compared to the abovementioned studies could be due to the stricter glucose-controlled reference category selection. In the cases, insulin sensitivity was similar in the late NGT ranges and IGT/DM giving similar kind of observations to that of the METSIM study [20]. The decline in overall $\beta$-cell secretion and first-phase insulin secretion in the background of already reduced insulin sensitivity (more prominent in cases, 40-50\% reduction in WBISI) could be the reason for reduced $\beta$-cell compensation and subsequent elevation of blood glucose levels in the late NGT and IGT/DM subjects. This was also evident when we compared the late NGT group and IGT/IFG after adjusting for age, gender, and BMI. Whole-body insulin sensitivity was not significantly different between the groups, however, there was a significant reduction in overall $\beta$-cell secretion $(p=0.013)$, firstphase insulin secretion $(\mathrm{p}=0.004)$, and $\beta$-cell compensation $(\mathrm{p}<0.001)$ in the IGT ranges.

Overall $\beta$-cell secretion (IGI 120) and first-phase insulin secretion (IGI 0-30) were not significantly different in case subjects across the FG category, however across two-hour glucose levels, there was a significant reduction in both IGI $120(\mathrm{p}=0.005)$ and IGI $30(\mathrm{p}<0.001)$. Compared to the increase in fasting glucose levels, an increase in glucose at two-hour may better reflect the reduction in overall $\beta$-cell secretion and first-phase insulin secretion. The magnitude of decline was more in first-phase insulin secretion than in overall $\beta$-cell secretion ( $46 \%$ vs. $8 \%$ ) in the IGT range, compared to the reference two-hour category of $<84$ $\mathrm{mg} / \mathrm{dL}$. This is in agreement with a large-scale study conducted by Aoyama-Sasabe et al., in the Japanese population, where they have observed, a reduction in early-phase insulin secretion as the most important factor responsible for elevation of two-hour glucose levels during OGTT in isolated IGT subjects [27]. Restoration of first-phase insulin secretion by dietary and therapeutic means has been proposed as a method not only for the prevention of diabetes but also for the prevention of cardiovascular events [28].

Controls for this study were subjects without a family history of T2DM. However, family members of these subjects were not tested for T2DM. Some may have undiagnosed T2DM as routine periodic health check-up is not common in this region. Cases and controls were not matched for gender and age (mean age 23 years vs. 28 years, higher in controls, $\mathrm{p}<0.001$ ), which was a big limitation of the study. To reduce the confounding effects, the analysis was matched for age, gender, and BMI. Being a cross-sectional study, a cause-effect relationship could not be deduced from the present study.

\section{Conclusions}

In conclusion, we had observed a continuous and significant decline in $\beta$-cell compensation starting from normal glucose tolerance to impaired glucose tolerance in both offspring of individuals with type-2 diabetes (cases) and controls. In the cases, the reduction in insulin sensitivity was not continuous from NGT to IGT ranges and was not significantly different between late NGT and IGT levels. The decline in first-phase insulin secretion was more pronounced than overall $\beta$-cell secretion in the IGT levels, compared to the late NGT state in cases. Even though the proinsulin levels during OGTT were increased from NGT to IGT ranges, 
a significant difference in relative hyperproinsulinemia with respect to the C-peptide levels was not observed between late NGT and IGT levels. Compared to a stricter glucose control group without a known family history of type- 2 diabetes mellitus, based on both fasting and two-hour plasma glucose levels, approximately $60 \%$ decline was observed in $\beta$-cell compensation and insulin sensitivity, in offspring of T2DM subjects in the impaired glucose tolerant state.

\section{Additional Information \\ Disclosures}

Human subjects: Consent was obtained or waived by all participants in this study. All India Institute of Medical Sciences (AIIMS) issued approval A-12/29.01.2017 and B14/28.11.2007. Animal subjects: All authors have confirmed that this study did not involve animal subjects or tissue. Conflicts of interest: In compliance with the ICMJE uniform disclosure form, all authors declare the following: Payment/services info: The study was funded by the Indian Council of Medical Research. Financial relationships: All authors have declared that they have no financial relationships at present or within the previous three years with any organizations that might have an interest in the submitted work. Other relationships: All authors have declared that there are no other relationships or activities that could appear to have influenced the submitted work.

\section{Acknowledgements}

The authors would like to acknowledge the guidance and constant support of Late Dr. A.C. Ammini (former Head, Department of Endocrinology, AIIMS) for completing the study, Shiji Binu and Leslie James for assistance in performing hormonal assays, and Mr. Manoj Srivasthava, Mrs. Jomimol John, and Dione Kurian for their help in recruiting participants for the study.

\section{References}

1. Kahn SE: The relative contributions of insulin resistance and beta-cell dysfunction to the pathophysiology of type 2 diabetes. Diabetologia. 2003, 46:3-19. 10.1007/s00125-002-1009-0

2. Bergman RN, Phillips LS, Cobelli C: Physiologic evaluation of factors controlling glucose tolerance in man: measurement of insulin sensitivity and beta-cell glucose sensitivity from the response to intravenous glucose. J Clin Invest. 1981, 68:1456-1467. 10.1172/jci110398

3. DeFronzo RA, Eldor R, Abdul-Ghani M: Pathophysiologic approach to therapy in patients with newly diagnosed type 2 diabetes. Diabetes Care. 2013, 36:127-138. 10.2337/dcS13-2011

4. Faerch K, Vaag A, Holst JJ, Hansen T, Jørgensen T, Borch-Johnsen K: Natural history of insulin sensitivity and insulin secretion in the progression from normal glucose tolerance to impaired fasting glycemia and impaired glucose tolerance: the Inter99 study. Diabetes Care. 2009, 32:439-444. 10.2337/dc08-1195

5. Turner RC, Cull CA, Frighi V, Holman RR: Glycemic control with diet, sulfonylurea, metformin, or insulin in patients with type 2 diabetes mellitus: progressive requirement for multiple therapies (UKPDS 49). UK Prospective Diabetes Study (UKPDS) Group. JAMA. 1999, 281:2005-2012. 10.1001/jama.281.21.2005

6. Cersosimo E, Solis-Herrera C, Trautmann ME, Malloy J, Triplitt CL: Assessment of pancreatic $\beta$-cell function: review of methods and clinical applications. Curr Diabetes Rev. 2014, 10:2-42. 10.2174/1573399810666140214093600

7. Yeckel CW, Taksali SE, Dziura J, et al.: The normal glucose tolerance continuum in obese youth: evidence for impairment in beta-cell function independent of insulin resistance. J Clin Endocrinol Metab. 2005, 90:747-754. 10.1210/jc.2004-1258

8. Mitrakou A, Kelley D, Mokan M, Veneman T, Pangburn T, Reilly J, Gerich J: Role of reduced suppression of glucose production and diminished early insulin release in impaired glucose tolerance. N Engl J Med. 1992, 326:22-29. 10.1056/NEJM199201023260104

9. Ramachandran A: Epidemiology of diabetes in India: three decades of research . J Assoc Physicians India. 2005, 53:34-38.

10. Praveen EP, Kulshreshtha B, Khurana ML, et al.: Obesity and metabolic abnormalities in offspring of subjects with diabetes mellitus. Diabetes Technol Ther. 2010, 12:723-730. 10.1089/dia.2009.0163

11. The Expert Committee on the Diagnosis and Classification of Diabetes Mellitus: Report of the expert committee on the diagnosis and classification of diabetes mellitus. Diabetes Care. 2003, 26:5-20. 10.2337/diacare.26.2007.s5

12. Tai MM: A mathematical model for the determination of total area under glucose tolerance and other metabolic curves. Diabetes Care. 1994, 17:152-154. 10.2337/diacare.17.2.152

13. Matsuda M, DeFronzo RA: Insulin sensitivity indices obtained from oral glucose tolerance testing: comparison with the euglycemic insulin clamp. Diabetes Care. 1999, 22:1462-1470. 10.2337/diacare.22.9.1462

14. Matthews DR, Hosker JP, Rudenski AS, Naylor BA, Treacher DF, Turner RC: Homeostasis model assessment: insulin resistance and beta-cell function from fasting plasma glucose and insulin concentrations in man. Diabetologia. 1985, 28:412-419. 10.1007/BF00280883

15. Stadler M, Pacini G, Petrie J, Luger A, Anderwald C, RISC Investigators: Beta cell (dys)function in nondiabetic offspring of diabetic patients. Diabetologia. 2009, 52:2435-2444. 10.1007/s00125-009-1520-7

16. Retnakaran R, Shen S, Hanley AJ, Vuksan V, Hamilton JK, Zinman B: Hyperbolic relationship between insulin secretion and sensitivity on oral glucose tolerance test. Obesity (Silver Spring). 2008, 16:1901-1907. 10.1038/oby.2008.307

17. Herzberg-Schäfer SA, Staiger H, Heni M, et al.: Evaluation of fasting state-/oral glucose tolerance testderived measures of insulin release for the detection of genetically impaired $\beta$-cell function. PLoS One. 
2010, 5:e14194. 10.1371/journal.pone.0014194

18. Cnop M, Vidal J, Hull RL, et al.: Progressive loss of beta-cell function leads to worsening glucose tolerance in first-degree relatives of subjects with type 2 diabetes. Diabetes Care. 2007, 30:677-682. 10.2337/dc061834

19. Arslanian SA, Bacha F, Saad R, Gungor N: Family history of type 2 diabetes is associated with decreased insulin sensitivity and an impaired balance between insulin sensitivity and insulin secretion in white youth. Diabetes Care. 2005, 28:115-119. 10.2337/diacare.28.1.115

20. Stancáková A, Javorský M, Kuulasmaa T, Haffner SM, Kuusisto J, Laakso M: Changes in insulin sensitivity and insulin release in relation to glycemia and glucose tolerance in 6,414 Finnish men. Diabetes. 2009, 58:1212-1221. 10.2337/db08-1607

21. Gujral UP, Narayan KM, Kahn SE, Kanaya AM: The relative associations of $\beta$-cell function and insulin sensitivity with glycemic status and incident glycemic progression in migrant Asian Indians in the United States: the MASALA study. J Diabetes Complications. 2014, 28:45-50. 10.1016/j.jdiacomp.2013.10.002

22. Dagogo-Jack S, Askari H, Tykodi G: Glucoregulatory physiology in subjects with low-normal, high-normal, or impaired fasting glucose. J Clin Endocrinol Metab. 2009, 94:2031-2036. 10.1210/jc.2008-1348

23. Ehrmann DA, Sturis J, Byrne MM, Karrison T, Rosenfield RL, Polonsky KS: Insulin secretory defects in polycystic ovary syndrome. Relationship to insulin sensitivity and family history of non-insulin-dependent diabetes mellitus. J Clin Invest. 1995, 96:520-527. 10.1172/JCI118064

24. Røder ME, Porte D Jr, Schwartz RS, Kahn SE: Disproportionately elevated proinsulin levels reflect the degree of impaired B cell secretory capacity in patients with noninsulin-dependent diabetes mellitus. J Clin Endocrinol Metab. 1998, 83:604-608. 10.1210/jcem.83.2.4544

25. Gastaldelli A, Ferrannini E, Miyazaki Y, Matsuda M, DeFronzo RA: Beta-cell dysfunction and glucose intolerance: results from the San Antonio metabolism (SAM) study. Diabetologia. 2004, 47:31-39. 10.1007/s00125-003-1263-9

26. Burns SF, Bacha F, Lee SJ, Tfayli H, Gungor N, Arslanian SA: Declining $\beta$-cell function relative to insulin sensitivity with escalating OGTT 2-h glucose concentrations in the nondiabetic through the diabetic range in overweight youth. Diabetes Care. 2011, 34:2033-2040. 10.2337/dc11-0423

27. Aoyama-Sasabe S, Fukushima M, Xin X, et al.: Insulin secretory defect and insulin resistance in isolated impaired fasting glucose and isolated impaired glucose tolerance. J Diabetes Res. 2016, 2016:1298601. 10.1155/2016/1298601

28. Charlotte B, Neil M, Martin W : Targeting beta-cell preservation in the management of type 2 diabetes . $\mathrm{Br} \mathrm{J}$ Diabetes. 2017, 17:134-144. 10.15277/bjd.2017.148 